\title{
Desain dan Pengembangan Engsel Pintu Menggunakan Aplikasi Metode Elemen Hingga
}

\author{
Mohammad Kurniadi Rasyid ${ }^{1, a)}$ \\ ${ }^{1}$ Dosen Tetap Program Studi Teknik Mesin ITI, \\ J1. Raya Puspiptek Serpong, Tangerang Selatan-Banten, Indonesia, 15320 \\ ${ }^{\text {a) }}$ kurniadirasyid@gmail.com (corresponding author)
}

\begin{abstract}
Abstrak
Penelitian ini bertujuan mencari model engsel pintu dengan desain sederhana namun mempunyai kualitas yang baik. Rancangan engsel pintu ini harus seefisien mungkin dengan biaya yang tidak besar namun mampu menahan beban tanpa perubahan bentuk atau rusak. Empat model desain dibuat dan dianalisis. Computer Aided Design (CAD) perangkat lunak digunakan dalam perancangan ini. Pertama-tama model CAD dibuat dan kemudian dianalisis melalui perangkat lunak rekayasa Solidwork. Analisis elemen hingga dilakukan oleh perangkat lunak ini. Analisis difokuskan pada jenis bahan yang biasa digunakan untuk engsel pintu, yaitu stainless steel. Pembebanan untuk setiap engsel dibuat sama. Pada keempat model di analisis lendutan dan tegangan yang terjadi kemudian di evaluasi. Hasilnya menunjukkan bahwa model nomor dua terbaik dari sisi kekuatan juga paling sedikit deformasi.
\end{abstract}

Kata Kunci : CAD,elemen hingga, engsel pintu

\begin{abstract}
This study focuses on modeling door hinge. The design of this hinge should be as efficient as possible at a cost that is not great but is able to withstand loads without deformation or damaged. Four design concepts were made and analyzed. Computer Aided Design (CAD) software used in this design. First of all the CAD modes are created and then analyzed through software engineering Solidwork. Finite element analysis was done by this software. Analysis focused on types of materials used, namely stainless steel. In all four models in the analysis of deflection and stresses that occur later in the evaluation. The results show that the model second best when it is used for door hinge.
\end{abstract}

Keywords : CAD, Finite Element, door hinge

\section{PENDAHULUAN}

Latar belakang penelitian ini dibuat adalah karena banyak engsel pintu yang mudah mengalami kerusakan dalam penggunaannya. Permasalahan kerusakan pada engsel tersebut diduga karena permasalahan defleksi atau pun permalahan lendutan yang disebabkan karena kesalahan desain kontruksi. Karena banyak rakyat Indonesia yang tingkat ekonominya masih lemah maka perlu dicari tahu desain engsel pintu yang bisa dibeli dengan harga murah namun mempunyai kualitas yang baik saat digunakan.

Hingga saat ini penelitian tentang engsel pintu sederhana dan murah serta multi fungsi belum ada yang membuat dan meneliti. Penelitian terkait engsel pintu kebanyakan untuk penggunaan pada otomotif. Penelitian More dan Jadhav [1] menyimpulkan deformasi yang terjadi pada engsel pintu mobil masih pada nilai yang diijinkan dan tegangan kerja dibawah ultimate stress dari materialnya. Parmashwar, EjazKittur, P.S. Shivakumar Gouda [2] menyatakan dalam penelitiannya untuk engsel pintu otomotif bahwa tegangan yang terjadi pada bagian atas engsel lebih besar dari bagian bawahnya.

Tujuan penelitian ini untuk mencari desain engsel pintu bangunan dengan desain yang ekonomis namun mempunyai ketahanan yang lebih baik dalam menahan berat pintu.

\section{LANDASAN TEORI}

Dalam proses perancangan atau pembuatan desain dari suatu produk penggunaan metode elemen hingga sering digunakan terutama dalam melakukan berbagai analisis kekuatan. Keunggulan dari metode ini adalah karena sangat efisien dan cukup akurat. Metode ini pertama kali diperkenalkan oleh Richard Courant pada tahun 1943. Cara kerja analisis menggunakan Metode Elemen Hingga berdasarkan cara memandang sebuah objek dengan memecahnya menjadi bagian elemen yang sangat banyak dan sangat kecil.

Proses ini diawali dengan pembuatan model geometri 3D yang kemudian di transformasikan menjadi 
model elemen hingga yang terdiri dengan banyak Elemenelemen node yang jauh lebih kecil. Proses perubahan ini meliputi perubahan dari model matematika menjadi model numerik. Keakuratan Metode Elemen Hingga sangat tergantung jumlah node. Semakin banyak elemen maka semakin akurat. Metode Elemen Hingga sangat sering digunakan untuk menganalisis tegangan dan kekuatan dari benda berikut kharakter yang terjadi akibat pembebanan. Metode Elemen Hingga dapat mempermudah menyelesaikan persoalan yang mungkin sulit untuk diselesaikan dengan perhitungan secara analitis. Metode ini terbukti telah memecahkan banyak kasus yang ada.

Dasar-dasar metode Elemen Hingga sudah ada sejak tahun 1940-an dan sejak tahun 1970-an diterapkan dan dirumuskan secara formal. Pada awalnya metode ini digunakan dibidang teknik penerbangan untuk perhitungan kekuatan struktur pesawat pada industri pesawat terbang, namun sekarang metode Elemen Hingga ini telah diterapkan dalam berbagai bidang teknik.

Salah satu cara mengetahui nilai tegangan maksimum yang terjadi pada suatu elemen benda adalah dengan cara menghitung penggabungan tegangan regangan dengan menggunakan formula tegangan Von Mises.

\section{METODE PENELITIAN}

\section{Desain Penelitian}

Proses desain dimulai dengan memgumpulkan data desain dari engsel pintu yang dijual dipasaran. Beberapa model dibuat desainnya untuk dianalisis. Metode pemilihan menggunakan matriks keputusan Pugh [3] [4]. Gambar 1 menunjukkan proses desain yang digunakan dalam merancang engsel pintu.

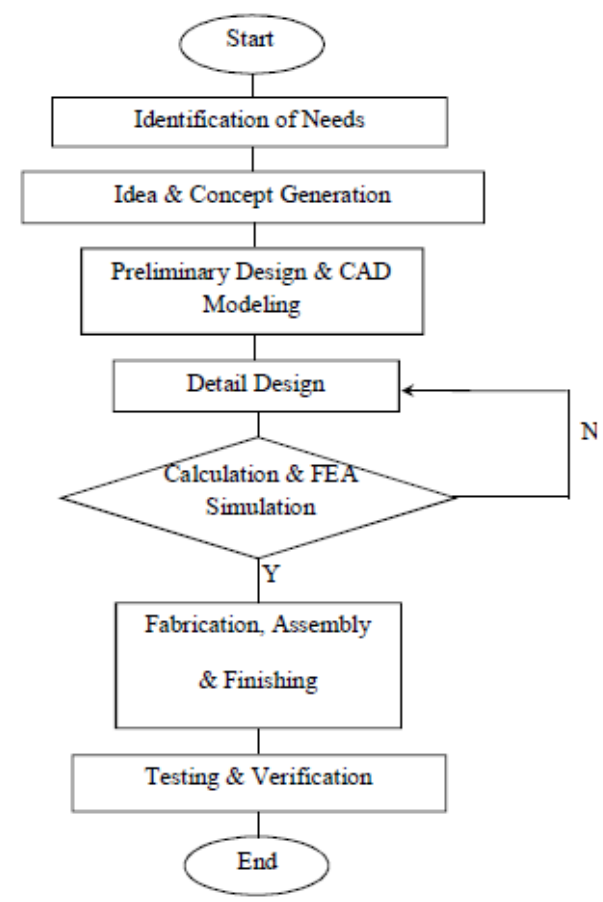

Gambar 1. Desain Penelitian

\section{Pemodelan}

Empat konsep desain dibuat dan pemilihan konsep terbaik menggunakan pugh's concept. Computer Aided Design (CAD) perangkat lunak digunakan dalam merancang model-model dari engsel. Selanjutnya modelmodel CAD yang sudah dibuat dianalisis melalui perangkat lunak rekayasa Solidwork. Analisis elemen hingga dilakukan oleh perangkat lunak ini terhadap modelmodel tadi. Analisis difokuskan pada jenis bahan yang biasa digunakan untuk engsel pintu, yaitu stainless steel. Lendutan dan tegangan yang terjadi kemudian dievaluasi.

\section{Tahapan Penelitian}

- Empat model desain engsel pintu dibuat menggunakan perangkat lunak dari Computer Aided Draft Design (CADD).

- Kemudian model-model engsel dari CADD ini dianalisis melalui perangkat lunak rekayasa Solidworks.

- Analisis difokuskan pada bahan stainless steel. Untuk pembebanan akibat berat pintu dipilih berat yang sama untuk setiap engsel yaitu $300 \mathrm{~N}$.

- Lendutan dan tegangan yang terjadi pada setiap model dianalisis dan dibandingkan.

\section{Model Elemen Hingga dan Analisis}

Untuk menganalisis tekanan maksimum yang bekerja pada engsel pintu, digunakan software FEA (Finite Element Analyze) pada empat model 3D CAD yang dibuat dengan bantuan software SOLIDWORKS. Model yang dipilih untuk dianalisis ditunjukkan pada gambar 2, 3, 4 dan gambar 5 .

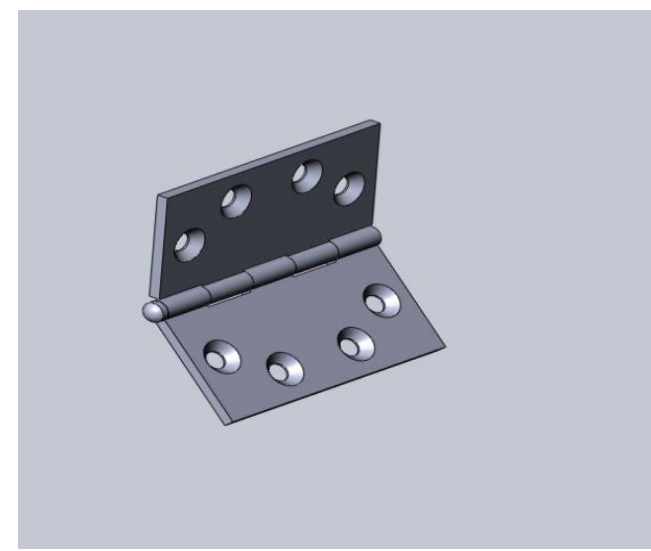

Gambar 2. Model 1 


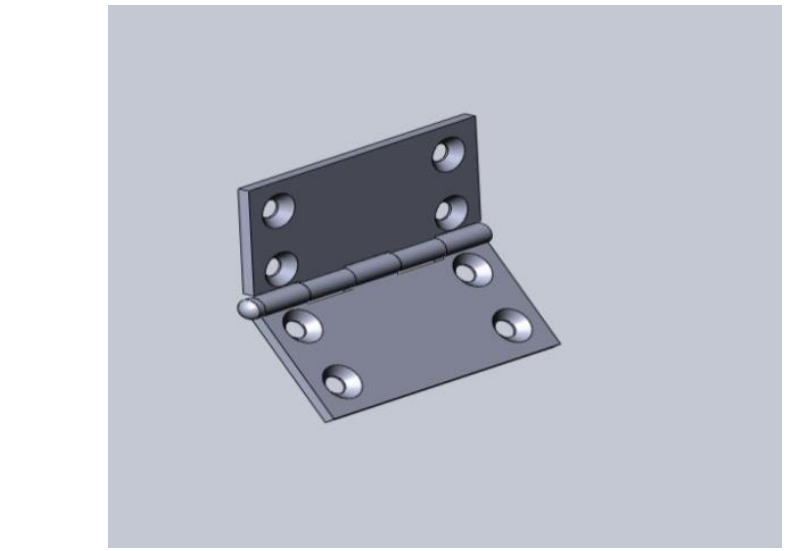

Gambar 3. Model 2

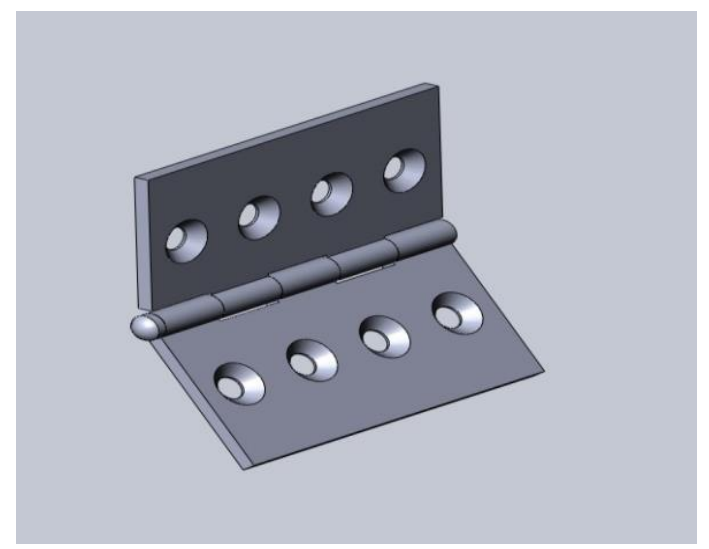

Gambar 4. Model 3

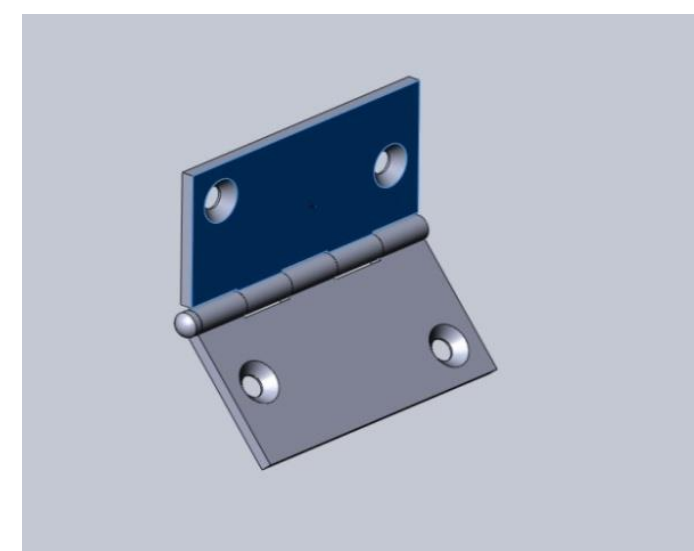

Gambar 5. Model 4

Guna pembuatan model Elemen Hingga diperlukan data masukan berupa dimensi dan jenis material Selanjutnya dipilih jumlah node, besar beban, dan lokasi serta jenis tumpuan. Terakhir dari dari hasil analisis didapatlah gaya dalam, stress, displacement, reaksi tumpuan, dan lain-lain. pada tabel 1 .

Sifat mekanik bahan yang digunakan ditunjukkan
Tabel 1. Mechanical properties of Stainless steel

\begin{tabular}{ll} 
Mechanical Properties & Metric \\
\hline Tensile Strength, Ultimate & $370 \mathrm{Mpa}$ \\
Tensile Strength, Yield & $205 \mathrm{Mpa}$ \\
Elongation at Break & $36.5 \%$ \\
Reduction of Area & $66.0 \%$ \\
Modulus of Elasticity & $200 \mathrm{Gpa}$ \\
Bulk Modulus & $140 \mathrm{Gpa}$ \\
Poissons Ratio & 0.290
\end{tabular}

\section{HASIL DAN PEMBAHASAN}

Pertama-tama dilakukan analisis pemilihan model desain terbaik menggunakan metoda Pugh. Pada tabel 2 dapat dilihat hasil penilaian untuk masing-masing kriteria setiap model

Tabel 2. Pugh decision matrix design selection untuk model $1,2,3$ dan 4

\begin{tabular}{|c|c|c|c|c|}
\hline \multirow[t]{2}{*}{ Kriteria } & \multicolumn{4}{|c|}{ Model } \\
\hline & 1 & 2 & 3 & 4 \\
\hline Functionality & 8 & 8 & 8 & 8 \\
\hline Assembly & 8 & 8 & 8 & 9 \\
\hline Maintainability & 8 & 8 & 8 & 9 \\
\hline Design simplicity & 7 & 8 & 7 & 9 \\
\hline Safety & 8 & 8 & 8 & 8 \\
\hline Quality & 8 & 8 & 8 & 8 \\
\hline Ergonomics & 7 & 7 & 7 & 7 \\
\hline Cost & 7 & 7 & 7 & 8 \\
\hline Total Average & 61 & 64 & 61 & 66 \\
\hline
\end{tabular}

Scoring Scale; Bad (1) - Excellent (10)

Dari tabel menggunakan analisis pugh didapat bahwa model 2 dan 4 lebih baik dibandingkan kedua model lain,

Guna melihat analisis dari sisi kekuatan dan kestabilan struktur selanjutnya dilakukan analisis elemen hingga. Hasil analisis terdiri dari tegangan dan deformasi yang terjadi pada model 3D CAD yang dirancang yang kemudian dianalisis melalui simulasi metode elemen hingga menggunakan software SOLIDWORKS. Gambar 7, 8, 9 dan 10 menunjukkan tegangan von Mises yang terjadi pada model engsel akibat pembebanan. area merah mewakili tegangan mak simum von Mises dimana engsel akan sangat terpengaruh karena beban yang bekerja di atasnya, sementara warna biru sebaliknya menunjukkan tegangan minimum.

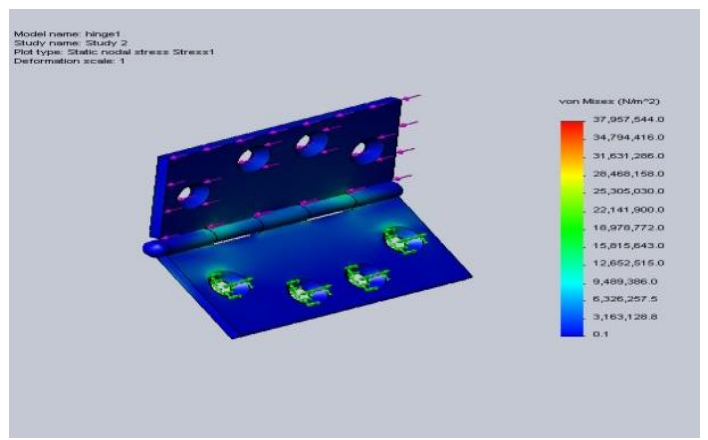

Gambar 7. Analisis tegangan model 1 


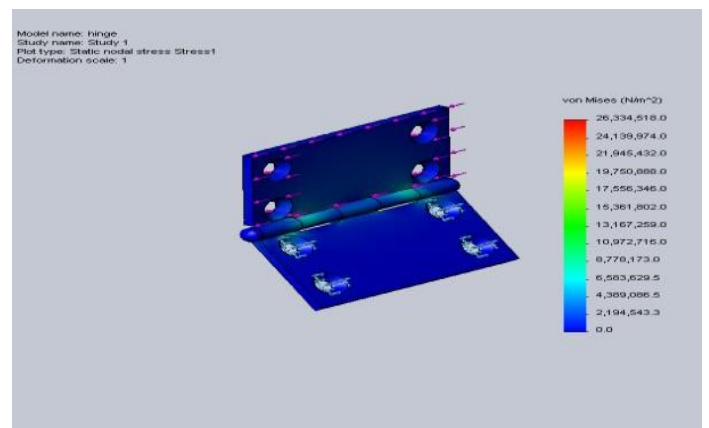

Gambar 8. Analisis tegangan model 2

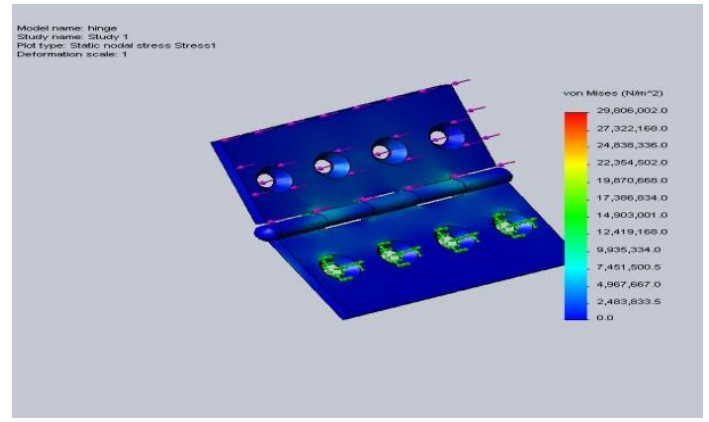

Gambar 9. Analisis tegangan model 3

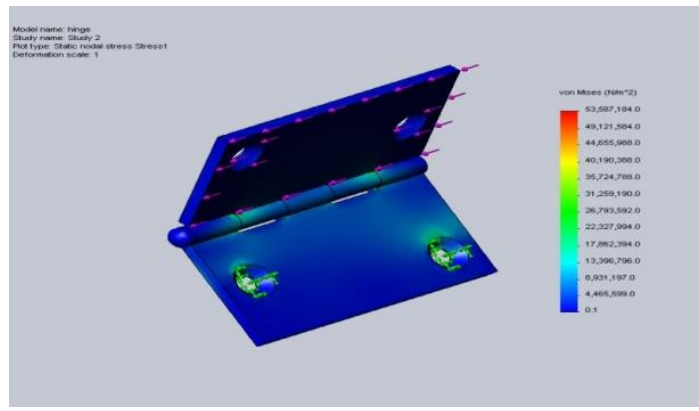

Gambar 10. Analisis tegangan model 4

Rangkuman hasil analisis tegangan yang terjadi pada model 1, 2, 3 dan 4 ditunjukkan pada tabel 3 .

Tabel 3. Tegangan yang terjadi pada setiap model

\begin{tabular}{cll}
\hline Model & Tegangan Von Mises & $\begin{array}{l}\text { Node } \\
\text { Nr. }\end{array}$ \\
\hline $\mathbf{1}$ & $3.79575 \mathrm{e}+007 \mathrm{~N} / \mathrm{m}^{\wedge} 2$ & 9794 \\
\hline $\mathbf{2}$ & $2.63336 \mathrm{e}+007 \mathrm{~N} / \mathrm{m}^{\wedge} 2$ & 10131 \\
\hline $\mathbf{3}$ & $4.61209 \mathrm{e}+007 \mathrm{~N} / \mathrm{m}^{\wedge} 2$ & 9940 \\
\hline $\mathbf{4}$ & $5.35872 \mathrm{e}+007 \mathrm{~N} / \mathrm{m}^{\wedge} 2$ & 9888 \\
\hline
\end{tabular}

Hasil analisis numerik sebagaimana terlihat pada tabel 3 menunjukkan bahwa pada model $1,2,3$ dan 4 masingmasing terjadi tegangan yang besarnya $3.80 \times 10^{7} \mathrm{~N} / \mathrm{m}^{2}$, $2.63 \times 10^{7} \mathrm{~N} / \mathrm{m}^{2}, 4.61 \times 10^{7} \mathrm{~N} / \mathrm{m}^{2}$ dan $5.366 \times 10^{8} \mathrm{~N} / \mathrm{m}^{2}$. Nilai paling rendah berada pada model 2 . Dengan mengambil faktor keamanan 2 nilai-nilai tersebut masih berada pada nilai aman untuk material baja dengan tensile strength $370 \mathrm{Mpa}\left(3.7 \times 10^{8} \mathrm{~N} / \mathrm{m}^{2}\right)$ juga yield strength $2.05 \times 10^{8} \mathrm{~N} / \mathrm{m}^{2}$.

Hasil analisis untuk deformasi yang terjadi dapat dilihat pada Gambar 11, 12, 13 dan 14. Warna merah merepresentasikan deformasi maksimum karena beban yang bekerja di atasnya, sementara warna biru sebaliknya menunjukkan deformasi minimum.

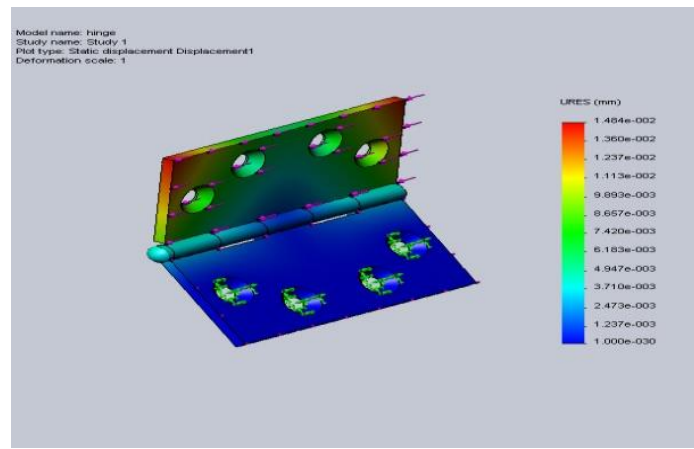

Gambar 11. Analisis deformasi model 1

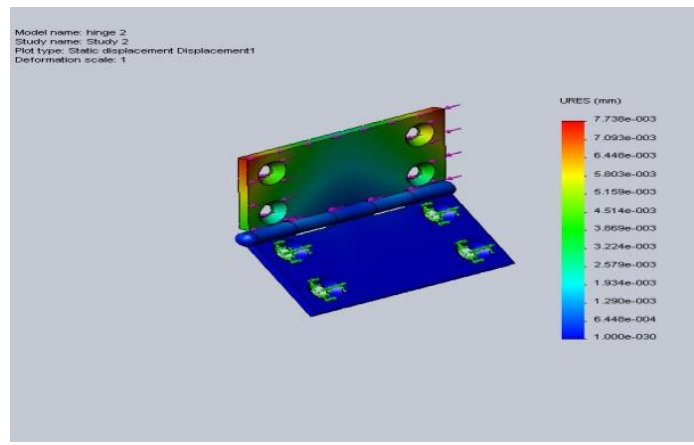

Gambar 12. Analisis deformasi model 2

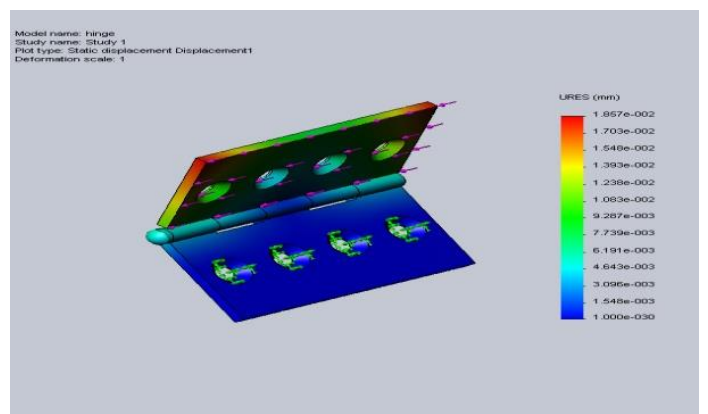

Gambar 13. Analisis deformasi model 3

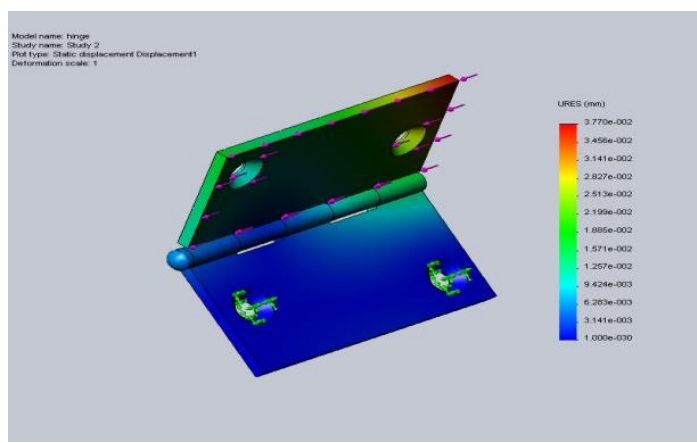

Gambar 14. Analisis deformasi model 4

Rangkuman hasil analisis deformasi yang terjadi pada model 1, 2, 3 dan 4 ditunjukkan pada tabel 4 . 
Tabel 4. Hasil analisis deformasi setiap model

\begin{tabular}{cll}
\hline Model & Deformasi & $\begin{array}{l}\text { Node } \\
\text { Nr. }\end{array}$ \\
\hline $\mathbf{1}$ & $0.0154395 \mathrm{~mm}$ & 1783 \\
\hline $\mathbf{2}$ & $0.00773799 \mathrm{~mm}$ & 1797 \\
\hline $\mathbf{3}$ & $0.0185738 \mathrm{~mm}$ & 1827 \\
\hline $\mathbf{4}$ & $0.0376978 \mathrm{~mm}$ & 1784 \\
\hline
\end{tabular}

Pada tabel 4 dapat dilihat bahwa pada model 1, 2, 3 dan 4 masing-masing terjadi lendutan yang besarnya $15.4 \times 10^{-3} \mathrm{~mm}, 7.7 \times 10^{-3} \mathrm{~mm}, 18.6 \times 10^{-3} \mathrm{~mm}$ dan $37.6 \times 10^{-3}$ $\mathrm{mm}$. Dari nilai ini terlihat model 2 lebih sedikit mengalami deformasi.

Hasilnya penelitian menunjukkan bahwa model nomor 2 dari engsel pintu adalah model terbaik karena tegangan dan lendutan yang terjadi lebih rendah dibandingkan model-model lainnya. Tegangan Von Mises yang terjadi pada model nomor 2 sebesar $2.63345 \mathrm{e}+007$ $\mathrm{N} / \mathrm{m} 2$ dan lendutannya sebesar $0.00736937 \mathrm{~m}$. Dari hasil diatas maka model 2 disarankan untuk dipilih.

\section{UCAPAN TERIMA KASIH}

Kami ingin mengucapkan terimakasih yang sebesar-besarnya terhadap semua pihak yang telah membantu khususnya Institut Teknologi Indonesia baik dari jurusan Mesin ITI juga LP3M-ITI.

\section{REFERENSI}

[1] N.D.More and T.A.Jadhav. Stress Analysis and Optimization of Car Door Hinge, International Engineering Research Journal (IERJ) Special Issue Page 1202-1205, June 2016, ISSN 2395-1621.

[2] Parmashwar, EjazKittur, P.S. Shivakumar Gouda. Analysis of Coach Driver Door with Hinge. International Journal of Innovative Research in Science, Engineering and Technology (IJIRSET) Vol. 4, no 6, June 2015

[3] Thakker, A., Jarvis, J., Buggy, M. and Sahed, A. 2009. 3DCAD conceptual design of the next-generation impulse turbine using the Pugh decision-matrix. Materials \& Design, 30(7): 2676-2684.

[4] Ulrich, K.T. and Eppinger, S.D. 2008. Product design and development. 4th Edition. New York: McGraw-Hill. 